\title{
Hybrid Electric Vehicle with Solar Integration using Bi directional DC-DC converter with Fuzzy Logic Control
}

\author{
Dev Prakash Chourasia ${ }^{1}$ Bhoopendra Singh ${ }^{2}$
}

${ }^{1}$ Research Scholar, Dept. of Electrical Engineering, University Institute of Technology, RGPV, Bhopal, Madhya Pradesh, India,

${ }^{2}$ Professor, Dept. of Electrical Engineering, University Institute of Technology, RGPV, Bhopal, Madhya Pradesh, India,

To Cite this Article

Dev Prakash Chourasia and Bhoopendra Singh, "Hybrid Electric Vehicle with Solar Integration using Bi directional DC-DC converter with Fuzzy Logic Control", International Journal for Modern Trends in Science and Technology, Vol. 07, Issue 02, February 2021, pp.-01-08.

Article Info

Received on 12-January-2021, Revised on 26-January-2021, Accepted on 29-January-2021, Published on 01-February-2021.

\section{ABSTRACT}

In this paper, a sunlight-based hybrid electric vehicle is planned on MATLAB Simulink. In this a primary fuel source which sun based and a helper source which is battery is utilized to fabricate a bidirectional DC-DC converter. In General thought, an electric vehicle uses a battery that is charged from an external force gracefully, anyway sunlight-based PV modules are used to charge a battery by strategies for fascinating radiation from the sun and changing over it into electrical force (Photovoltaic Effect) by proposed procedure. The electrical capacity to batteries got from sun powered PV modules, which might be connected either in course of action or equivalent and charge regulators. To cross a conclusive force point in the sunlight-based board, additionally Maximum Power Point Tracker (MPPT) regulator is used [3]. The sun powered PV part is executed utilizing a fuzzy based MPPT strategy. In the control framework for bidirectional DC-DC converter, an ANFIS framework is utilized to diminish the blunders and give a DC yield to DC machine which speaks to the Electric Vehicle. The utilization of Solar gives limitless energy and diminishes the expense of different other options. The advantage of ANFIS and Fuzzy joined framework gives the best accuracies and proficiency in the framework as contrasted and conventional PI based which is a more calculative control framework. The yield voltage of bidirectional DC-DC converter is about $430 v$ to drive the electric vehicle. The advantage of this plan is low count intricacy by utilizing ANFIS and Fuzzy based MPPT calculation for Photovoltaic module[3].

KEYWORDS:HEV (Hybrid electric vehicle), LV(low voltage), DS(dual source), HV(high voltage), FC(fuel cell), MPPT (Maximum Power Point Tracking), HESS (hybrid energy storage framework), BDC(bi-directional converter)

\section{INTRODUCTION}

Due to contamination brought about by petroleum product, new energy sources have been ceaselessly evolved. These days, inserted energy storage frameworks in flow age electric vehicles are generally founded on the Li-particle batteries which, with high energy thickness, can give long separation perseverance to electric vehicles. While contrasted with the super capacitor, the reaction of Li-particle batteries is more slow than that of super capacitors. Thusly, so as to make electric vehicles practically identical to fuel vehicles with respect to 
quick transient speeding up, energy, and long-separation perseverance, a hybrid energy storage framework (HESS) comprising of Li-particle batteries and super-capacitors is applied to electric vehicles. For the advancement of electric vehicles, upgrading the energy storage gadget is basic, and it is important to think about expanding the limit of the battery, while diminishing the size and weight of the battery to build the charging rate. The innovations for worldwide transportation are commanded by inward burning Engine powered vehicle that prompts significant risk to Green gas emanation. Despite the fact that the worldwide transportation innovation halfway moved to Hybrid fuels and battery electric vehicle. These innovation enhancements are not pulled in the worldwide client as a result of its expense and its similarity. Our point is to fabricate a minimal effort Solar Powered EV [13] that would meet the prerequisites of the worldwide client. EV are the subsequent fate of transportation since it diminishes the utilization of petroleum products to a bigger degree. Created and creating nations are empowering utilization of electric vehicles because of its productivity and assumed green innovation. In spite of the fact that charging of electric vehicles should be eco-accommodating, reports deny it. As charging the electric vehicle battery is again from matrix which is empowered by the utilization of non-renewable energy sources, it can't be eco-accommodating any more. Bridling the [4] solar power to charge an electric vehicle battery is the eco-most amiable choice to charge an electric vehicle. To streamline the power yield from solar board, Maximum Power Point Tracking (MPPT) is actualized. MPPT keeps up the activity of the board at maximum power point with the goal that the productivity of the board is expanded[3].

DC-DC converters which

assume a significant job in hybrid energy storage framework have been grown quickly throughout the years. Through a progression of advancements, an assortment of DC-DC converters are proposed. It has been indicated a separated bi-directional DC-DC converter with complex structure can change over a huge power transmission. Another zero-swell changing DC-to-DC converter with the coordinated attractive innovations is first proposed in by S. Cuk, and the application is fruitful. Confined interleaved DC/DC converter presents the idea of three-winding coupled inductors, yet it is progressively appropriate for power transmission. Polycrystalline solar boards are utilized in light of the fact that, creation of polycrystalline solar boards are more straightforward and financially savvy. Warmth resilience of polycrystalline solar boards is lower when contrasted with mono crystalline solar boards[6]. Solar board put on side perspective on the vehicle is 80 watt, front view has 20 watt and top perspective on vehicle is 400 watt. Hence absolutely 500 watts solar boards were set in SPEV. The top view solar boards are put even and different boards are puts in a 30-degree inclined position. Subsequently, 500watt power is created from inbuilt solar boards on the vehicle during direct daylight. Projection see guarantees the review of 500 watt board plans in SPEV structure.

\section{STRUCTURE OF PAPER}

The paper is organized as follows: In Section 1, the introduction of the paper is provided along with the structure, important terms, objectives and overall description. In Section 2 we discuss related work. In Section 3 we havepresented the proposed work. In Section 4we have discussed the controller and the controlling technique.Section 5 we have shown the simulation results and also described them .In the section 6 we have shown the the flow chart of the operating mode of the proposed converter. Section 7 tells us about the future scope and the section 8 concludes the paper with acknowledgement and references.

\section{OBJECTIVES}

The objectives of this work are

- To do extensive research work on electric vehicle system

- To improve the system performance by the use of ANFIS and fuzzy logic controller[3].

- To improve the performance of the electric vehicle system by integration of solar array along with batteries, so as to have longer run of the vehicle.

\section{RELATED WORK}

There are numerous works that have been done related to $\mathrm{HEV}$ and in the field of the solar integration of the HEV

Ching-Ming Lai[1]et. alproposed the Development of a Bidirectional DC/DC Converter with Dual-Battery Energy Storage for Hybrid Electric Vehicle System.The circuit setup, activity, consistent state examination, and shut circle control of the proposed BDC are talked about as per its three methods of power move.Additionally, the recreation and exploratory outcomes for a $1 \mathrm{~kW}$ 
model framework are given to approve the proposed converter.Manivannan $\mathrm{S}^{[2]}$ et. al SOLAR POWERED ELECTRIC VEHICLE. Ozone depleting substance discharge from transportation is one of the major ecological issues and its outflow rate is expanding at quicker rate. So solar power for transportation can take care of this issue. The point of proposed work is to contribute an innovation that supports Green energy; consider a situation we could utilize a solar energy to charge electric vehicle that too solar boards are inbuilt in the vehicle .

SushuruthSadagopan ${ }^{[3]}$ et. al A Solar Power System for Electric Vehicles with Maximum Power Point Tracking for Novel Energy Sharing. This paper displays another framework design which utilizes the power created from the photovoltaic (PV) boards utilized for charging batteries of solar powered electric vehicles. It has power frameworks for solar powered electric vehicles and solar powered lattice which is associated with a charging station or a center point. A few electric vehicles might be accused of its own photovoltaic board and the center point, which thusly is charged by a huge limit photovoltaic board or by the electric network on the off chance that the power gave by the board isn't adequate. When all the batteries associated with the framework arrive at a specific maximum charge limit, abundance energy from the vehicles and the center point is siphoned into the lattice, consequently using the energy that would have in any case been squandered. With fuel costs on the ascent, contracting supplies and an unnatural weather change issues, solar energy has become a zone of center for strategy producers and the administration, internationally. This paper presents another framework engineering for charging solar power electric vehicles. It effectively charges the batteries of solar powered vehicles with negligible utilization of the energy from the framework and furthermore permits the overabundance energy to be siphoned back to the network in this manner using the energy that would have in any case been squandered.

Revathi B.[4] et. al Solar Charger for Electric Vehicles. Our reliance on petroleum derivatives is radically re-duced by the consolidated utilization of solar energy and Electric Vehicle (EV) charging. Right now, solar charger for electric vehicle is planned and created. A dc-dc help converter is utilized to support the solar board voltage to station battery voltage and Maximum Power Point Tracking (MPPT) is done to enhance the yield from solar board. A buck converter is utilized to step down the station battery voltage to electric vehicle battery voltage. The consistent voltage and steady current techniques for charging are utilized to charge the vehicle battery. A total recreation investigation of the framework is done in the SIMULINK condition of MATLAB.

[5] B.Bendjediaet. al This paper bargains a point by point study, control and energy the board of a solar vehicle Multisource Power Supply.

[6] Fred Chiouet. al Solar Energy for Electric Vehicles. A few energy productivity ventures have been performed on Weber State University grounds in the previous years. The accomplishment is surprising. This paper will address the structure of a pilot venture, Solar Charging Station, through understudy's senior task for instruction and research. Understudies will get familiar with the hypothesis of solar Photovoltaic (PV) frameworks and to manufacture an exploratory solar station to charge the electric bicycles and electric cruiser. The framework will be shown for two new courses, Renewable Energy and Solar PV Systems.

John Connors ${ }^{[7]}$ et. al On the Subject of Solar Vehicles and the Benefits of the Technology..This paper studies the history and eventual fate of solar and electric vehicles and gives an outline of a commonplace solar vehicle. A vehicle with an impression of $8 \mathrm{~m} 2$ can create $1600-2400$ watts or 2-3 horsepower given current photovoltaic efficiencies. Expecting 100\% proficient cells, the vehicle would in any case produce just $11 \mathrm{hp}$ at early afternoon. Therefore, it is probably not going to see solar vehicles created in huge amounts.

\section{PROPOSED WORK}

There IN this section we will discuss the proposed converter MATLAB circuit.

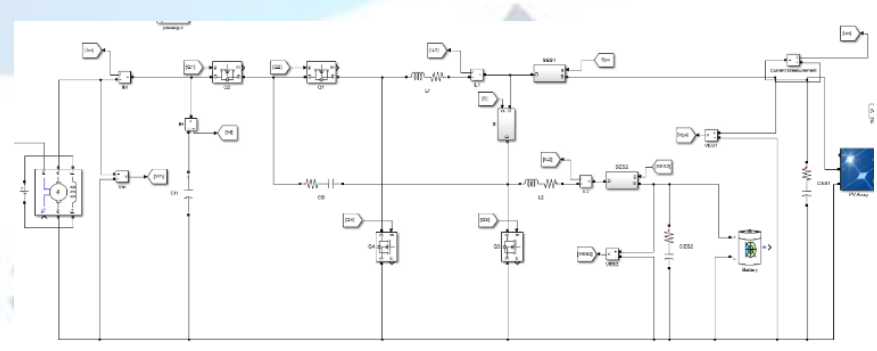

\section{Figure 1: PV array based circuit design for PV based} Hybrid electric vehicle

In the above converter we have integrated the solar PV array with the fuzzy logic controller and the ANFIS controller for controlling the converter operating modes.In this we have used the fuzzy with the SPWM which will shown in the further section. 


\section{IV.CONTROLLER AND CONTROLLING TECHNIQUE}

The below figue 2 shows theFinal control technique for MPPT is based on Fuzzy based Sinusoidal Pulse Width Modulation.

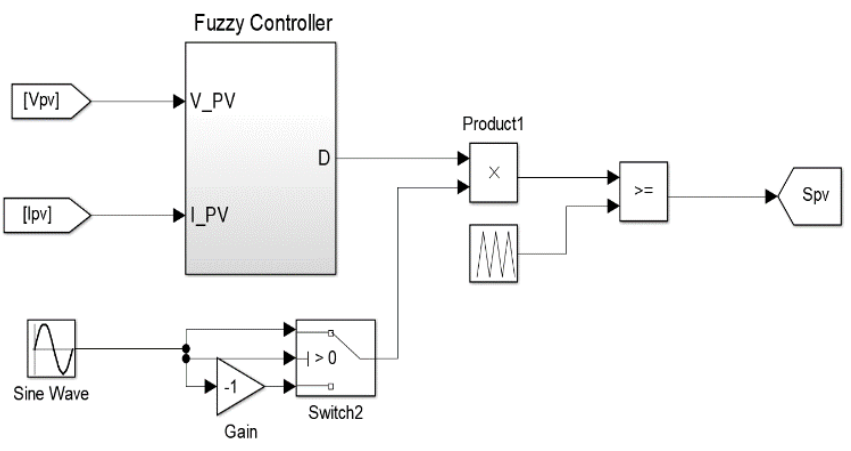

Figure 2: Fuzzy logic base Sinusoidal PWM combined logic for MPPTobjective

In figure 4.10 below, final control system with ANFIS for bi directional DC-DC converter is shown.

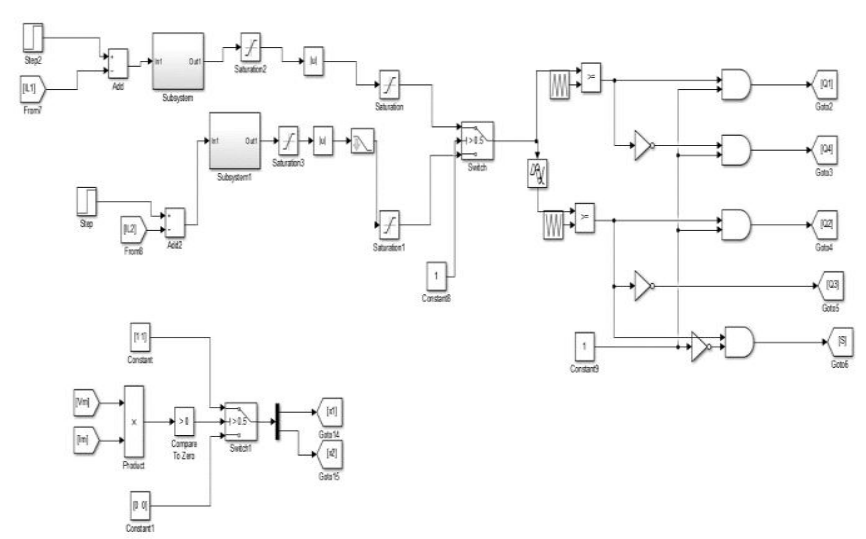

Figure 3 : Bidirectional DC-DC converter control system with ANFIS modelling

\section{V.SIMULATION RESULTS}
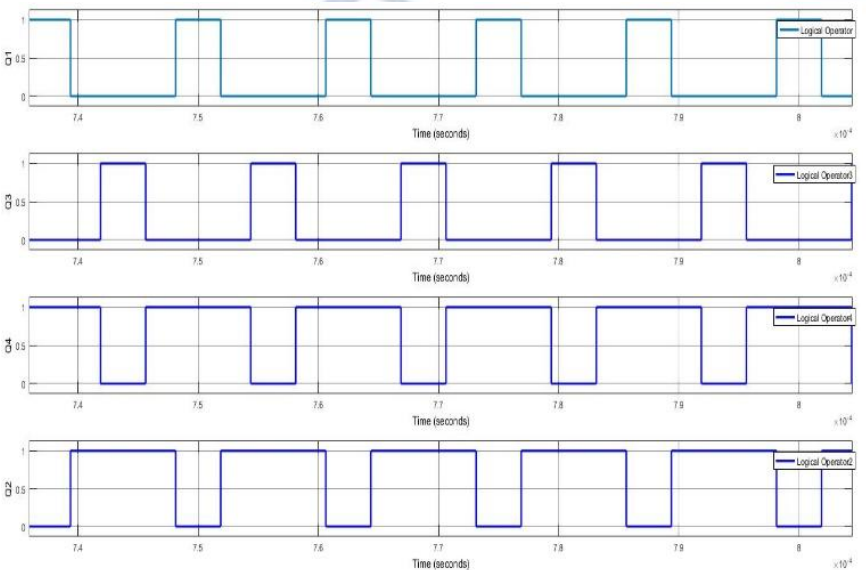

Figure 4: Waveform for $Q 1, Q 2, Q 3$ and $Q 4$

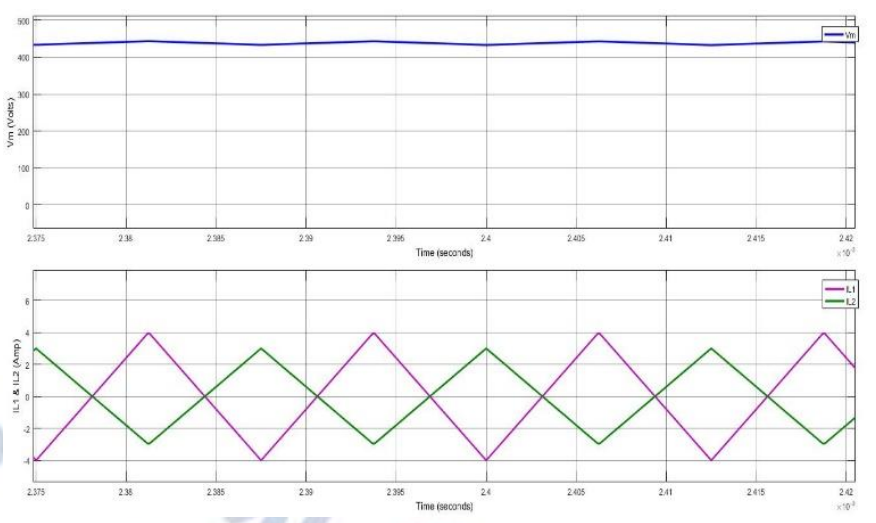

Figure 5: waveform for low-voltage DS powering mode Vm and IL1\&IL2

Figure 5 represents the waveform for the LV dual-source (DS) powering mode in which there is output voltage $(\mathrm{Vm})$ and IL1\&IL2 shown. This simulation result shows that both sources providing the supply to the motor and due to which they increases the two input voltages. Which results in the dc-bus voltage $\mathrm{Vm}$ of $430 \mathrm{~V}$.

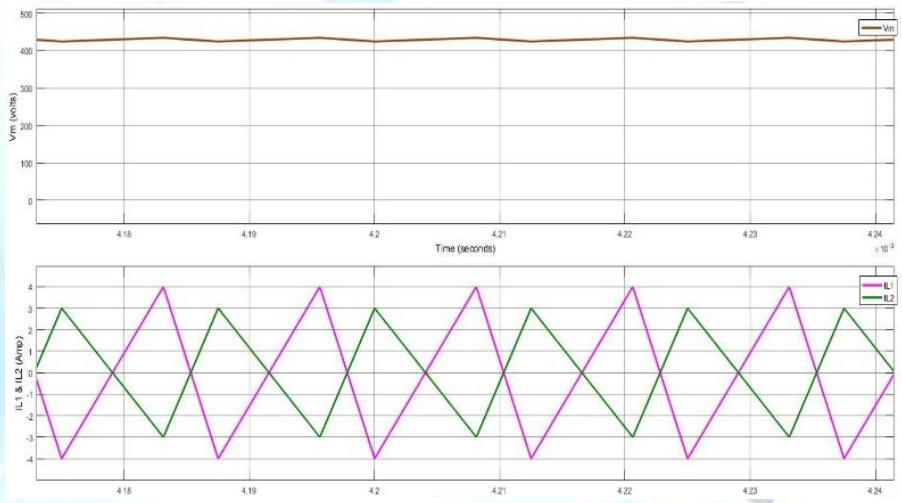

Figure 6: waveform for HV dc-bus energy-regenerating mode Vm and IL1\&IL2

Figure 6 is the details of the power flowing from HV dc bus to main and auxiliary energy storage.the inductor current IL1\& IL2 are flowing in opposite direction to input power.
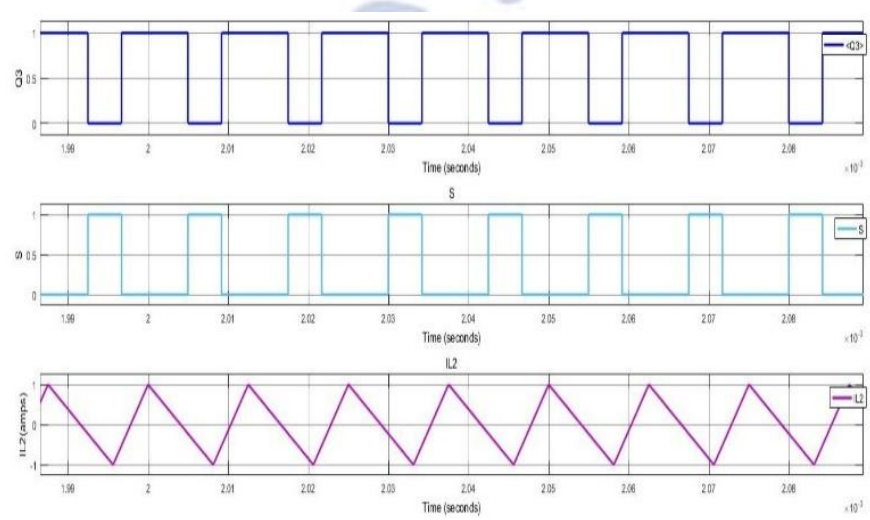

Figure 7: Q3,Vm and IL2 for the LV DS buck mode

4 International Journal for Modern Trends in Science and Technology 
Figure 7 represents the LV DS buck mode (buck mode-ES1 to ES2) in which the control switch S and the Q3 act as an SR (synch. rect.) and the inductor current IL2 is shown .from the above fig as we can observe the inductor current has a peak when Q3 is ON and it is negative maximum when $\mathrm{S}$ is $\mathrm{ON}$.
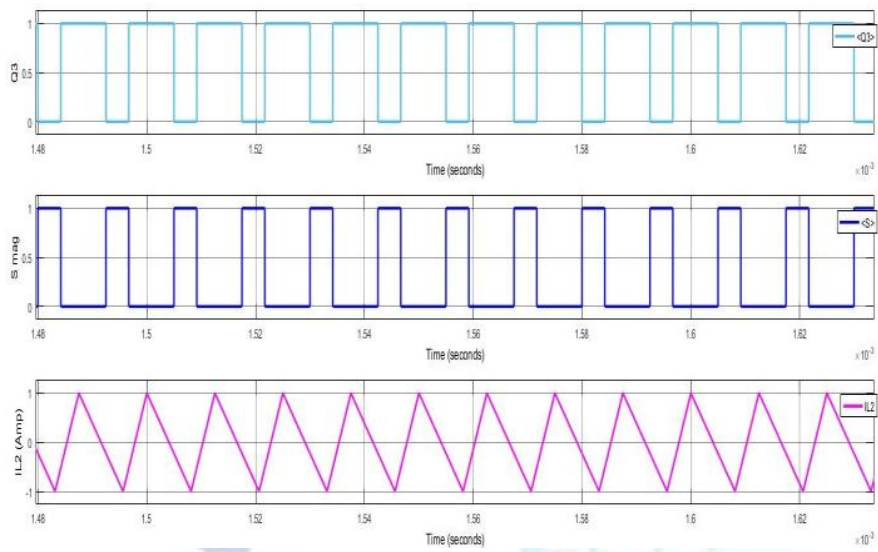

Figure 8: waveform for Q3 ,S, IL2 for the LV DS boost mode

Figure 8 represents the LV DS boost mode (boost mode-ES2 to ES1) in which the control switch Q3 and the S act as an SR (synch. rect.) and the $\mathrm{I}_{\mathrm{L} 2}$ is shown from the above fig as we can observe the inductor current has a peak when Q3 is ON and it is negative maximum when $\mathrm{S}$ is $\mathrm{ON}$.

From the above figures 7 and 8 we can see that the $\mathrm{I}_{\mathrm{L} 2}$ are opposite to each other which shows the capability of the proposed BDC to conduct the bidirectional power flow between the main energy storage i.e. PV array and the auxiliary storage.

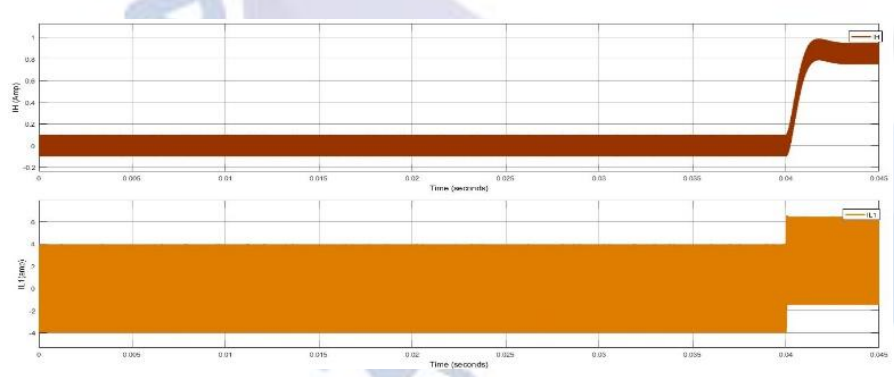

Figure 9: IL1 and IH output current chart

In figure 9 the waveform of DC-bus current (IH) and inductor current (IL1) is shown as we can see that $\mathrm{IH}$ is changed from 0 to $0.8 \mathrm{~A}$ and the inductor current changes from 0 to $2.5 \mathrm{~A}$. As displayed in the fig the high side current IH and the IL1 current are adjusted in such a way to deliver approx $370-\mathrm{W}$ power to the low side DS to high side DC-bus.

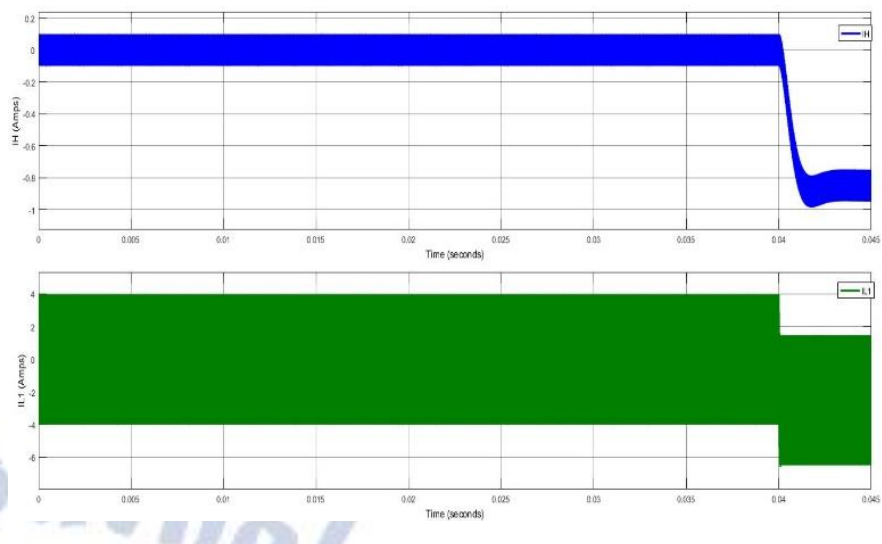

Figure 10: controlled step change in current IH and IL1

Figure 10 shows simulation results of controlled current step change in $\mathrm{HV}$ dc bus energy regenerating mode in which the dc bus current changes 0 to $-0.89 \mathrm{~A}$ while the inductor current changes from 0 to $-2.5 \mathrm{~A}$.The negation of both the currents represents the ability to successfully flow the power in reverse direction .

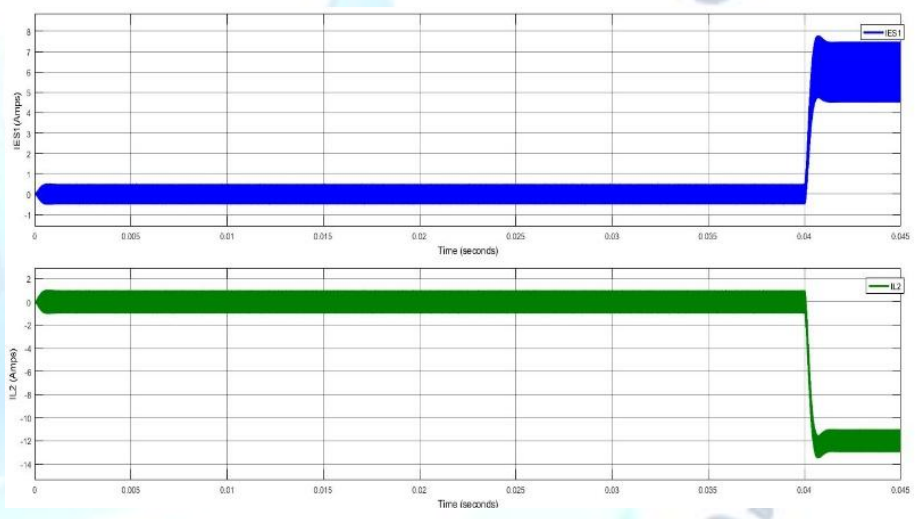

Figure 11: step current change in LV-DS-buck-mode: IES1 \& IL2

Figure 11 represents the simulation results of the step current change in the LV-DS-buck-mode. The high side current IES1 and theIL2 are delivering the power between the LV-DS. Again, as we are getting the negative currents represents the power flow was successfully reversed. The main energy storage current IES1 and the IL2 deliver the power from $\mathrm{ES} 2$ to ES1. 

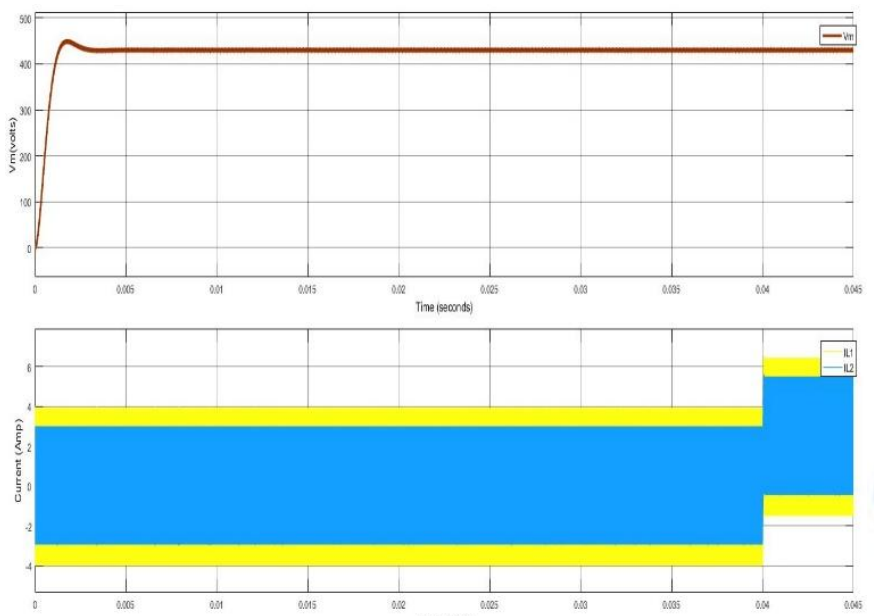

Figure 12: Output DC Voltage for Solar HEV and IL1 and IL2 Chart

In figure 12 , the output $\mathrm{DC}$ vol., which is about 430 volts, is achieved for the DC machine representing the electric vehicle. In addition, the current waveforms are shown for IL2 and IL3.
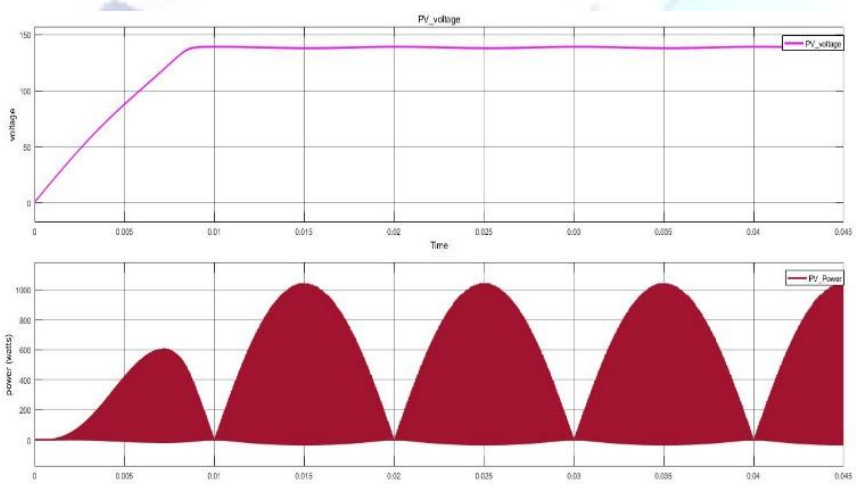

Figure 13: PV voltage and power for solar

In figure $13, \mathrm{PV}$ voltage and power for solar are shown for output power of $\mathbf{1} \mathbf{~ K w}$ for solar power generation.After time the pv voltage get stabilized and we get the power about $1 \mathrm{kw}$.

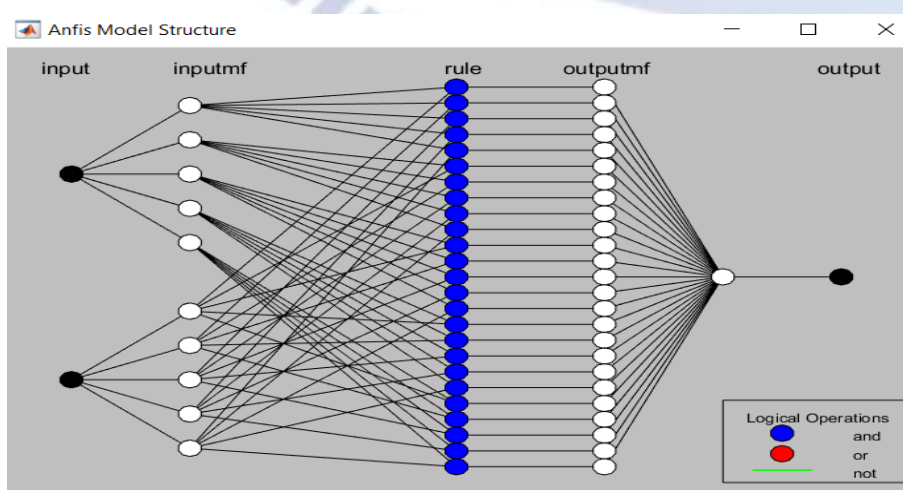

Figure 14: ANFIS model Structure
In figure 14, ANFIS structure is shown, as according to rules, inputs and outputs are assigned.

A Surface Viewer: dcdcanf2

File Edit View Options

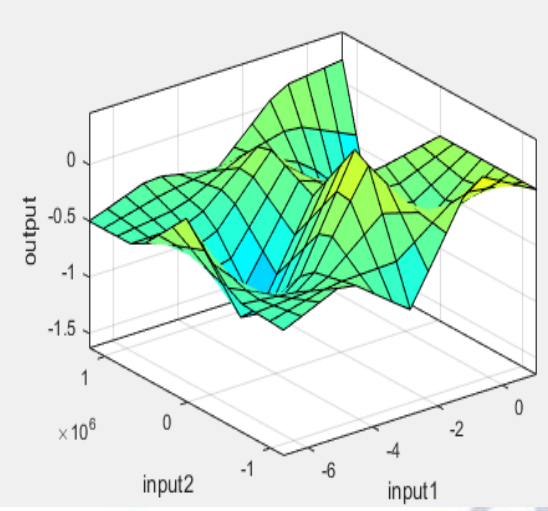

Figure 15: FIS Surface View

In figure 15, The ANFIS file surface view for sugeno rules are shown. In figure 16, MPPT tracking graphs are shown.

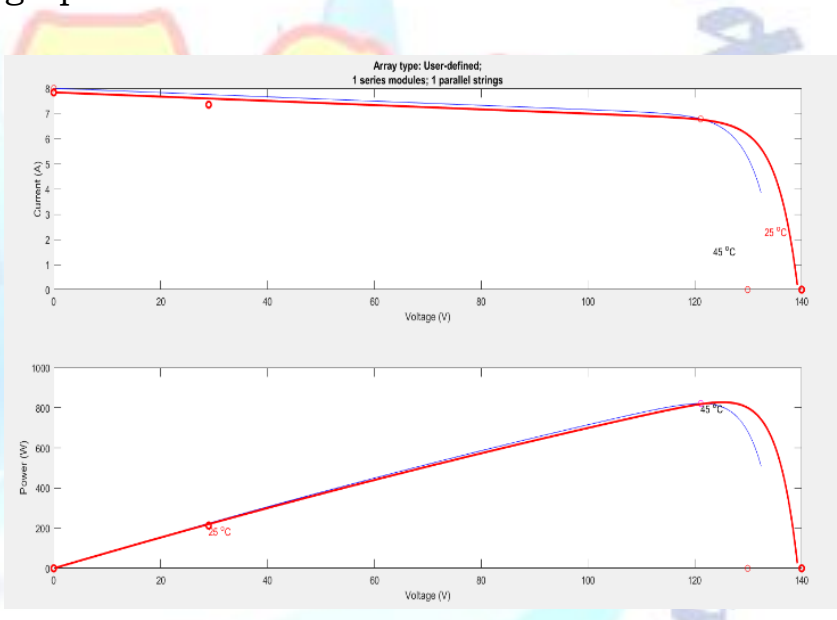

Figure 16: MPPT Output for Solar Panel

In figure 16, MPPT output for solar PV modules is shown. Represents the waveform of PV current and the power generated by the solar array.

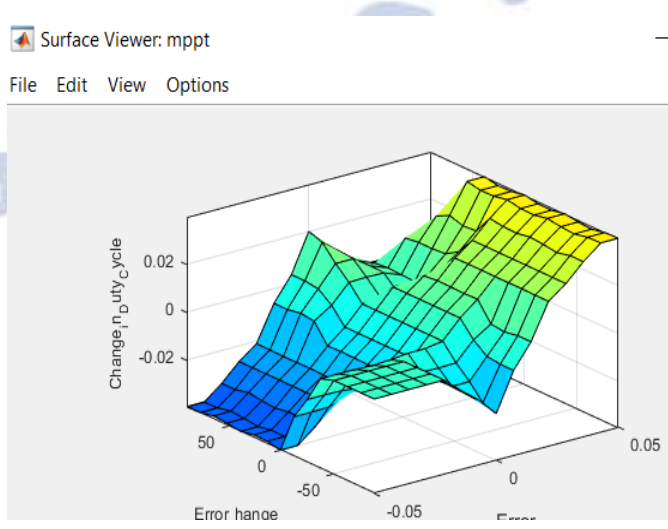

Figure 17: MPPT Surface View 
In figure 17 , the surface view rules for fuzzy MPPT logic is shown.which is the plot between the change in duty cycle and error \& change in error means it shows how these changes with the change in the duty cycle of the proposed converter

\section{VI.FLOW CHART FOR OPERATING MODE SELECTION}

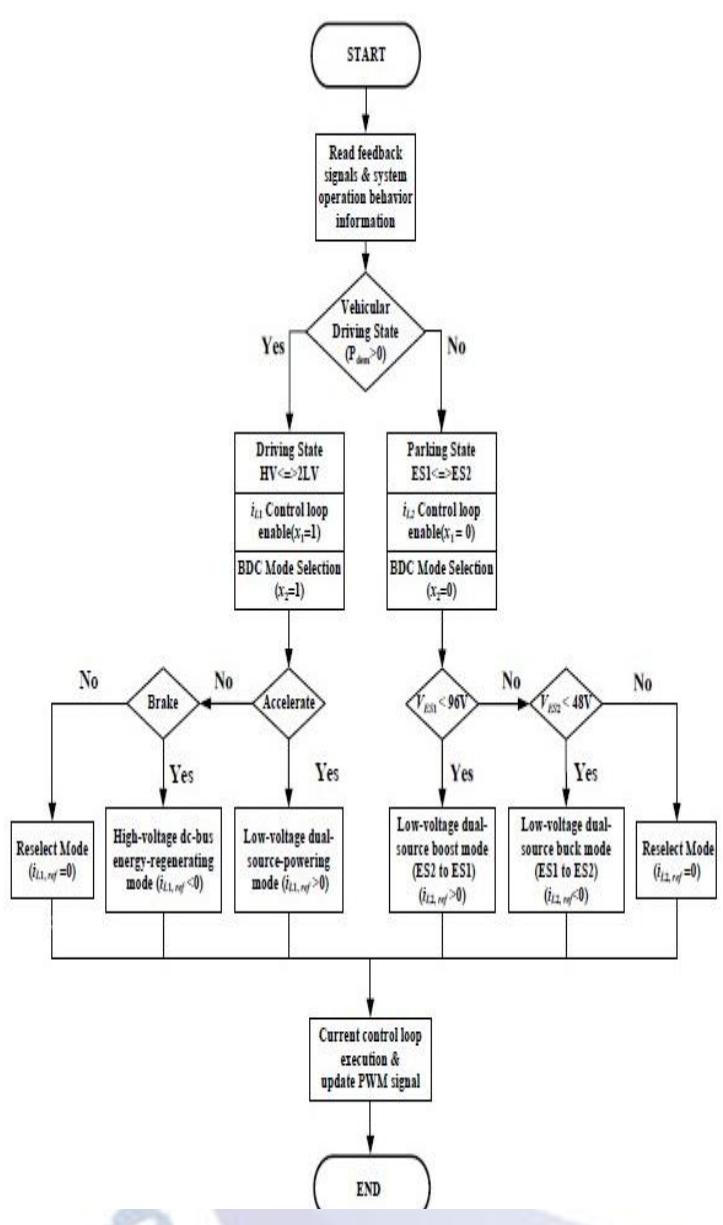

Figure 18:flow chart for mode selection

\section{Table 1}

\begin{tabular}{|c|c|c|c|}
\hline \multicolumn{4}{|c|}{ CONTROL SCHEME } \\
\hline MODES & $\mathbf{x}_{\mathbf{1}}$ & $\mathbf{x}_{\mathbf{2}}$ & RELATION \\
\hline $\begin{array}{c}\text { High-voltage dc-bus } \\
\text { energy-regenerating } \\
\text { mode }\end{array}$ & 1 & 1 & $\begin{array}{c}\text { Pdem }>0, \text { iL1, ref } \\
<0\end{array}$ \\
\hline $\begin{array}{c}\text { Low-voltage } \\
\text { dual-source-powering } \\
\text { mode }\end{array}$ & 1 & 1 & $\begin{array}{c}\text { Pdem }>0, \text { iL1, ref } \\
>0\end{array}$ \\
\hline $\begin{array}{c}\text { Low-voltage } \\
\text { dual-source boost } \\
\text { mode }\end{array}$ & 0 & 0 & $\begin{array}{c}\text { Pdem }<0, \text { VES1 }< \\
96 \mathrm{~V}, \text { iL2, ref }>0\end{array}$ \\
\hline $\begin{array}{c}\text { Low-voltage } \\
\text { dual-source buck } \\
\text { mode }\end{array}$ & 0 & 0 & $\begin{array}{c}\text { Pdem }<0, \text { VES2 }< \\
48 \mathrm{~V}, \text { iL2, ref }<0\end{array}$ \\
\hline
\end{tabular}

In theabove figure 18 and in the Table-1 [1], the flow chart is shown for the various operating mode of the converter. According to the operating condition of the vehicle the converter, select the operating mode .Such as the power demand $\left(\mathrm{P}_{\mathrm{dem}}\right)$ of the different driving states and the dual source voltages (VES1, VES2).

\section{FUTURE SCOPE}

Solar energy vitality is beginning for all types of energy vitality. This energy vitality can be utilized in two different ways the Thermal course for example utilizing heat for dry, warm, cook or age of power or through the Photovoltaic course which changes over solar energy in to power that can be utilized for a bunch reason, for example, lighting etc. With its contamination free nature, for all intents and purposes unlimited supply and all over world scattering solar energy vitality is attractive energy vitality asset. Solar Energy can be used for shifted applications. In this way, the response to "Why Solar" question can be looked for from two alternate points of view: using solar energy vitality for lattice interactive and off-framework (counting hostage) power age.

\section{CONCLUSION}

The sun based controlled electric vehicle has a couple of benefits, for instance, fuel capable, decline in the tainting and gives calm activity. The paper considers about activity of the DC Machine in shut hover control according to the change in sun-oriented irradiance condition and change in set speed of an electric vehicle. The advantages of DC Machine are higher assessment of profitability, power thickness and speed ranges, which settles on decision of this motor, for various applications. The multiplication result speaks to that, for various voltage level of PV group, controlling of commitment example of the DC-DC converter, by then the set speed gets kept up. The traits of proposed sun-oriented PV based DC Machine driven electric vehicle and viability make it beneficially accommodating in method of DC Machine drives in different fields[2]. The proposed framework confirms the consistency of DC Machine through non-ordinary source by evacuating oil-based commodity and besides common responsive for life of the vehicle. The utilization of ANFIS and Fuzzy based control rationale improves the yield and [12]effectiveness of the sun oriented based hybrid electric vehicle framework with bidirectional DC-DC converter as appeared in the reenactment result segment[6]. 


\section{REFERENCES}

[1] Ching-Ming Lai, Yu-Huei Cheng, "Development of a Bidirectional DC/DC Converter with Dual-Battery Energy Storage for Hybrid Electric Vehicle System" 0018-9545 (c) 2017 IEEE

[2] Manivannan S, Kaleeswaran E, "SOLAR POWERED ELECTRIC VEHICLE” 978-1-5090-3498-7/16/\$31.00 C2016 IEEE

[3] SushuruthSadagopan, Sudeep Banerji, Priyanka Vedula, Mohammad Shabin, C.Bharatiraja, "A Solar Power System for Electric Vehicles with ANFIS for Novel Energy Sharing" Unrecognized Copyright Information DOI 10.1109/TIIEC.2014.28 978-1-4673-8922-8/16 \$31.00 C 2016 IEEE

[4] Revathi B. Sivanandhan S, Vaishakh Prakash, Arun Ramesh, Isha T.B, Saisurivaa G, "Solar Charger for Electric Vehicles" 978-1-5386-5744-7/18/\$31.00@2018 IEEE 1

[5] B.Bendjedia, A. Hadjadj , A. Benhouia, F. bouchafaa, M.Temmir, "Energy Management and control of a Solar Electric Vehicle" 978-1-4673-6673-1115/\$31.00 (C2015 IEEE

[6] Fred Chiou, "Solar Energy for Electric Vehicles" 978-1-4799-1802-7/15/\$31.00 O2015 IEEE

[7] John Connors, "On the Subject of Solar Vehicles and the Benefits of the Technology" 1-4244-0632-3/07/\$20.00 C2007 IEEE.

[8] Brian R. Borchers, Jonathan A. Locker, "ELECTRICAL SYSTEM DESIGN OF A SOLAR ELECTRIC VEHICLE" 06 August 2002 DOI: 10.1109/EEIC.1997.651282

[9] Michelangelo Grosso, Davide Lena, Alberto Bocca, Alberto Macii, Salvatore Rinaudo, ST-PolitoS.c.ar.1., Politecnico di Torino, STMicroelectronics, "Energy-Efficient Battery Charging in Electric Vehicles with Solar Panels" 978-1-5090-1131-5/16/\$31.00 @2016 IEEE .

[10] A. M. Alsomali, F. B. Alotaibi, Ali T. Al-Awami, "Charging Strategy for Electric Vehicles Using Solar Energy" 10 May 2018 DOI: 10.1109/SASG.2017.8356485

[11] Chaitanya Kanumilli, Amit Singh, Akshatha Ganesh, Madhurya Srinivas, "Plug in electric vehicle" 978-1-4673-6658-8/16/\$31.00 @2016 [EEE

[12] Vineeth .V Vincent,S.Kamalakkannan, "Advanced Hybrid System for Solar Car" ISBN: 978-1-4673-6408-9/13/\$31.00@20 13 IEEE

[13] M. Godoy Simaes, N. N. Franceschetti, J. C. Adamowski, "DRIVE: SYSTEM CONTROL AND ENERGY MANAGEMENT OF A SOLAR POWERED ELECTRIC VEHICLE” 0-7803-4340-9/98/\$10.00 01998 IEEE.

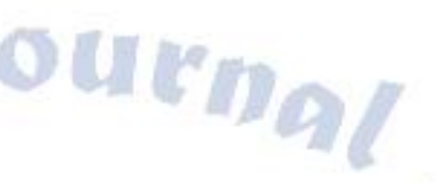

